\title{
Mapping Language Sexism and Gender Biases in Lumawig's Mythical Variants
}

\author{
Jonnelle D. Fagsao, Ed.D. \\ Mt. Prov. State Polytechnic College, \\ Bontoc, Mountain Province, Philippines
}

\begin{abstract}
This study deals with the influences and shifts of the male and female roles in Lumawig mythical variants common in the indigenous oral texts of the Kankanaeys and Bontoksin the Cordillera Administrative Region (CAR), Philippines. Basing from the literary variants, typical stereotyped portrayals and identification of biases were analyzed anchored in the book of Henry Beard and Christopher Cerf. Theoretically, it is focused on the improvement of Lumawig myths through gender bias and stylistics analysis at the word, sentence and discourse level. The language sexism part is based on the analysis of literary variations' usage of universal words on gender and on how the characters are described. Through character analysis females are described either as attractive, passive, obedient, dull and evil women. However, the male protagonist is depicted as cultural hero and rescuer. These biased character representations are discriminatory among men as they highlight their optimistic characteristics and illustrate female's lesser character in the Igorot culture. It shows also that the mythical variants did not manifest language sexism in the word level but rather focused in the sentence and discourse level.
\end{abstract}

Keywords: gender biases, language sexism, Lumawig myth, word-level, sentence-level, discourse level.

\section{Introduction}

In the realm of fictional literature, the folktale is the oldest and most popular kind of literature for it mirrors how people were depicted and portrayed stereotypically. As for the distinguishing interpretations of folk narratives, it is always expected that the women are characteristically described in a hasty manner like being weak folks whom wait for a valiant and courageous conqueror to save them or as sinful antagonists who oppose somebody's ideas. Women protagonists in local oral narratives are always very attractive and lovely with a stunning physical description, and they are also undecided and incapable to respond without the aid of their men protagonists.

Typically, these gender characteristics and sexist features of both women and men do occur stereotypically in oral narratives which people consider them as normal, usual and true. Definitely, this angle of vision is inappropriate as it develops gender biases against both women and men. Oral literature among the indigenous people particularly in the Philippines is generally the reflection of their beliefs and way of life. Such literature has been passed from generation to generation and had become part of their traditions and culture life.

One of the widely accepted and recognized stories by the Bontoks and the Kankanaeys of the hinterlands are the mythological narratives about the main characters of Lumawig myths. They are described as benevolent beings that use their powers and wisdom for the welfare and interest of the people in the society. The oral narratives of these local cultural heroes and heroines had been preserved through oral tradition. They are performed in a specific genre and tone and were chanted in traditional melodies which were impersonated by the locals. 
On the other hand, this study's main concern is to analyze the occurring problem concerning the variation of gender biases and linguistic sexism in the Lumawig's mythical variants that sprung up from the practice of language sexism and gender biases. The current study's explorations are based on mythological narrative characters of Lumawig myths that call attention to typical gender biases and linguistic sexism.

For this reason, the researcher is challenged to analyze the practical part that concentrates on the individual cultural characters most important description in the Lumawig's myth. It is intensively concentrated on the distinctive gender biases among the men and women cultural heroes of the mythical variants and the sexist language in the word and discourse level anchored in Mills (1995) model. Consequently, with these interpretations, readers will express themselves correctly and aesthetically, and confidently gaining awareness to the effective use of language skills (Çer, 2016). Educational researches indicate that when readers are taught regarding their language through relevant literature, their thinking and problem-solving skills will be developed; and they will start to be more comfortably associated to what they have learned with real-life (Safaa, 2015) as cited from Sinan, Demir, \& Dogan (2017).

\section{Review of Related Literature}

\section{On folklore}

According to Helen E. Lopez in her essay "Folklore and Literary Studies" (1993) cited from the study of Manochon (2009), people see folklore as a concept to be found in a special place called the "field." This field is inhabited by the folk society which is often regarded as peasant or agrarian. The most persistent element in this misconception is that folklore is always regarded as something antiquated, whose peculiar charm lies in the traditional and unique culture of the people. Toward the mid-1960s folklore expanded its definition to include everything of folk life. Today it is no longer exclusively rural or preindustrial. It exists in tension with other aspects of cultures in society.

\section{On Language Sexism}

As cited by Fetalvero (2016) in her research presented orally in HARDECC, La Trinidad, Benguet Province, Philippines, she mentioned that:

“...[Mills (2008) clarified] that sexist language conveys [an undesirable] depiction of women ... represented as abnormal and substandard to men.... Statements which are sexist contribute, promote or exploit unfair or irrelevant or [disrespectful] distinctions between sexes."

Another study on language sexism is conducted by He (2010) who studied the English language with reference to its morphological and syntactic features. According to her, "sexism in the morphological sense of words related to deviations and compounding and also in the presence of generic nouns and pronounce are very clearly evident." Likewise, also to Lei (2006) that the common forms of sexism in the language such as its formation, habitual association of professions to either both [sexes] and the words present are clearly limited in reference to one sex or the other, with female words tends to be critical at all.

\section{Stereotypical Sexual Roles/Biases}

It is essential to deal with the most significant expressions, namely gender stereotypes/biases. It is also important to focus and ponder on the clarifications and implications of such terminologies as they are critical and vital for acceptance particularly on the issues regarding sexual role biases as well as archetypal interpretations of the major characters in the oral texts.

Concerning gender distinctiveness, there are definite gender behaviors that can be considered as ways of performing that our values frequently connects with being a woman or a man. These behaviors are associated with positive descriptions that are regularly used to female attributes, such as dependent, expressive, inactive, delicate and free, non-emotional, violent, tough-skinned for masculine characteristics. Other examples of such stereotyped behaviors are exemplified with gender stereotypes that follow. Gender stereotypes are dominant in the Igorot culture and the people monitor these without observing. As Cranny-Francis et al. (2003) points out: 
It is a fundamentally reductive way of demonstrating entire groups of people by categorizing them with a few key features. Folks from the group who do not fit that stereotype are then said to be atypical (2003).

However, Moore also points out that:

"Females have come to be seen as obviously fostering, delicate and submitting. On the contrary, men are thought of as being more viable and less emotional than women. Masculinity stereotypes can be labeled by words such as unresponsive, physically sturdy, free, energetic, and forceful. At the same time, men are seen as detached, balanced and firm." (2014)

\section{Gender Biases}

Bias refers to the tendency to show prejudice against one group and favoritism towards another, or for one to be influenced so much by something that he or she does not judge things fairly. Biases spring up from the practice of stereotyping. Most people readily acknowledge the existence of stereotypes of race, ethnicity, age, social class, nationality, and sexual orientation, region of the country, religion, and gender. Stereotypes are manifested in many ways: advertising, television, movies, music, and literature. Stereotypes abound in children's books, where women are mommies, children live at home with two parents, people is white, and where boys are active, dependent, and fearful (Alsemi \& Law, 1998). There are biases enumerated by Henry Beard and Christopher Cerf in their book "The Official Political Correct Dictionary and Handbook".

\section{Theoretical and Conceptual Framework}

\section{Language and Literature}

Welleck and Warren (1942) as cited by Fagsao (2015) mentions that language is quite literally the material of the literary artist. Every literary work is merely a selection from the given language. Corpuz (2000) cited according to Bateson, argues that literature is a part of the general history of language and is completely dependent on it. In the context of this study, the myth as a literary piece is analyzed according to the way language is used, specifically on the choice of words, to attain the particular objective that is the gender biases and linguistic sexism.

\section{Language and Society}

Culture is a multifaceted, which includes art, religion, ethics, customs and other social elements such as literature that plays a significant role in the expression of social and traditions practices. The society is a product of philosophy and positioned in relation with culture which is similar to the literary text in its endless play of signs and difference in meaning and can be defined according to its culture (Fraenkel,1967; Shi \& Shang, 2017; Mastud, 2017). According to Noor (2015), language is the key instrument and medium by which gender ideologies are constructed, perpetuated, and propagated. When language is viewed in the broad confines of society and culture, it may be called "one facet of human behavior". All cultural activity or behavior is group activity or behavior and language is a shared activity. It has been handed down from generation to the next, and it follows a specific system or pattern.

In the Philippines today more than 80 indigenous languages are spoken. Of these, there are labeled major languages spoken being ranked by number of vernacular speakers. The other languages are generally known as minor languages. One of them is the Bontok language which is the focus of the study. Literary variants of Lumawig's myths were written in the Bontok language as stated by Chakas \& Mi-ing (2017), Puma-at (2015), and Bacwaden (2008).

The above studies as mentioned above focused on major languages that expressed on language sexism on popular media such as periodicals, textbooks, and literary texts. In as much as review of related literature were collected, studied and interpreted, nobody focused on language sexism and gender biases in Lumawig's myth within Mountain Province that enabled the researcher to study on how typical gender bias and language sexism were characterized among the mythological characters in Lumawig's literary variants.

Linguistic analysis plays a character in exploration because myths use words to express meaning. Content is sometimes best explained by its form. Most themes and meanings in Lumawig mythical variants can be known through anaphoric repetition and parallelism in phrases. Feminist 
Stylistics Analysis as one of the approaches used in this study can also expose the skeletal background of the text which is important in extracting the meaning in the word and discourse level.

\section{Mythical Variations}

Myths are the essential fragment of human culture, henceforth can be distributed as a detached unit that endures within human perception as Bokhari \& Masood (2018) defined. Myth is a story about the adventures of gods, sacred narratives, didactic tales, a prescribed set of storytelling norms featuring fantastic beings that connect to a body of stories throughout time which is part of the oral tradition that has been successfully passed from one generation to the next and from one society to another (Fagsao, 2015; Puma-at, 2015; Dixon, 2017). Because of this, it could be easily seen that variations in the tales are inevitable. The following are some views on the variations and changes made on the popular Lumawig's myth among the Igorots of Mountain Province, Philippines.

The Lumawig Bontoc myths according to Bacwaden (2008) are thus an integral part of the life of the Bontoc-Igorot. It is through them that the Bontoc-Igorot receives his intellectual, religious, and social structure. As cited by Corpuz (2000) Vandergrift claims that is a normal thing to happen for stories to have variations and be presented in different versions. In fact, she says, even literary theories, are subject to change. Everything in this world changes, including stories. The older the stories are, the more transmission and transmutation have they gone through.

\section{Feminist Stylistics Model of Analysis}

Centered on the study of Darweesh and Ghayadh (2016) and Ohood Ali Mohammed Saif AlNakeeb (2018) they revealed the main objectives of this model:

[...]is to show how the linguistic structures of a fictitious work, such as phonological, lexical, grammatical, semantic, and pragmatic create meaning, and to what extent they contribute to its overall meanings and effects. (2016)

The feminist part of the approach is pointing to draw attention to and altering the way the gender is exemplified, and its stylistic aspect is concerning on the explanation of sexism in texts and the exploration of the way that point of view, agency, metaphor, or transitivity are suddenly thoroughly related to matters of gender. (2018)

Stylistic analysis conferring to Short and Semino (2008), as what was cited by Darweesh and Ghayadh, is a linguistic criticism. Additionally, it endeavors to deliver an explanation which is objective and scientific, based on existing measurable documents, and applied in an organized way rather than personal feelings and desires.

This paper examines the deployment of gender biases as well as philological sexism in the mythical variants of Lumawig myths. It critically analyzes the literary variants taking into consideration their linguistic context gathered from the archival research. The paper discusses the Lumawig mythical variants using linguistic analysis anchored in feminist stylistics model by Mills (1995) in three levels: the word, the sentence, and the discourse basing it from the Mills' toolkit questions: a. are the words which are used gender specific?; b. are generic nouns used to refer to masculine?; c. how is gender named in the text?; and d. how is gender described in the text?

The paper also enumerates and discusses gender biases based from Beard and Cerf book, "The Official Politically Correct Dictionary Handbook" that enumerates many gender biases. Sentences and scenes considered as biases are presented here that focus on how the sexual category characters are labeled in the mythical variants. Representations are given below.

\section{Objectives}

This study is an attempt to analyze the gender biases and sexist language in the levels of the words, sentences, and discourse of the cultural characters in Lumawig's mythical variants. Specifically, it seeks to answer the subsequent problems below:

1. What are the common biases found in the mythical variants and how are the biases applied in the oral texts?

2. How is language sexism expressed in the Lumawig mythical variants in the level of the Word, the Sentence, and Discourse? 


\section{Methodology}

\section{Research Design}

Descriptive-qualitative type of research was used in the study. As a tool in the interpretation and evaluation of the selected oral texts, in-depth linguistic criticism using the feminist stylistics model by Sarah Mills was used to interpret the oral texts based in the level of the word, the sentence, and the discourse.

The narratives are presented both in the popular versions and other variations. They are analyzed according to how the male and female characters were portrayed. As a tool in the interpretation and evaluation of the selected oral texts, descriptive-comparative approaches as well as in-depth character analysis are used. The comparative approach analyzes the oral texts according to how the characters are described.

\section{Research Methodology}

The study starts with the first problem on the typical gender bias portrayals of males and females in the selected stories. In- depth character analysis is used to analyze the following biases which are the sexism, lookism, heightism, speciecism, and socioeconomism that are depicted in the texts. Finally, linguistic criticism aspect is used which focuses on the identification of sexist language in the wordlevel, sentence-level, and discourse-level. To present these discussions and analyses systematically, sentences and scenes quoted from the text is used.

\section{Results and Discussions}

The men and women in the society are essentially different as to what many approved based from the oral narratives that almost exclusively concentrating on the opposing traditions. However, there are current activities regarding gender stereotypes and biases that call into interrogation behind the depiction of both genders throughout oral narrative texts. Basing through the interpretation of Bontok and Kankanaey oral texts, it is quite noticeable that the depiction of women is questionably pale as compared to the male counterparts in the texts. This section provides the results and the discussions of the study. The analysis includes the in-depth interpretation on how the male and female characters of the Lumawig's mythical variants are described.

\section{Gender stereotypes in Lumawig literary variants}

In most oral texts in Bontok and Kanakaney culture, a strong peculiarity among the mythical characters shows. Individuals obtain such positive individualities, oftentimes a replication or image of what is considered to be the society's traditional standard, custom or desire.

On the following analysis of "The Adventures of Lumawig" among the Kankanaeys and the Bontoks, it provides the readers with an excess of multidimensional characters with such characteristics of prejudiced representations of the major characters to determine and discover. One is able to interpret critically on how both genders are depicted. While no one can argue that different critics will certainly respond differently particularly in oral tradition literature, there are also many primary counterparts referring to the usual image of gender's characteristics that come approximately as an outcome.

\section{Portrayal of Lumawig}

It appears that the character present in this myth who is depicted as an immortal being and the son of the great god Kafunyan. He is the hero who takes the journey which he prospered in the end as he overthrows and overcomes all difficult hindrances before him.

Being the protagonist, he portrays a significant role from the story's exposition to its conclusion. It is obviously described from the narratives that the only probable escape and recovery of the Igorots is Lumawig himself, the only heroic immortal and pagan god who can provide the people with endless contentment and prosperity.

Nevertheless, Lumawig is not portrayed only as an immortal one; he is also depicted as a very handsome, spirited and enthusiastic, tough and sturdy, respectable and decent, strong leader, magnificent and splendid, enigmatic and shadowy, and wealthy and prosperous. 
The literary variants concerning Lumawig present an indigenous character that explains the traditional male recommendation among the Bontoks and the Kankanaeys. As an immortal oral text written, the story of Lumawig contributes a customary masculine character with individual personality and performance that separates him from his feminine equivalents. His characteristics permit him to fill-in the resolute heroic roles fabricated almost specifically for him.

It was mentioned earlier that Lumawig is undoubtedly the hero of his story. Representing Bontok and Kankanaey values and traditions, Lumawig expresses the customary male principles of the Bontoks and the Kankanaeys, through both his heroic status and actions. His skill during tribal wars suggests respect from both the readers and those around him. However, Lumawig obtains appreciation and fame because of his charisma and cleverness as what he usually used more often than his physical ones to get rid of his difficulties particularly on his encounter with his brother-inlaw, Khumanab.

\section{Fukhan, Bugan, or Fugan}

Just as Lumawig's literary variants offer male's characters that depict the customary anticipations and social beliefs of their sexual characteristics, the story presents female characters that conform to social norms. Women from the different literary variants were also taken into consideration the gender roles of their period which is the development of their personalities that display the criteria of their time.

With the plot of the Lumawig's literary variants, Fukhan, Bugan or Fugan exists as a central character, with a significant role and an effect on the story. Throughout the story, Fukhan expresses many of the characteristics found in a traditional oral text. Except for Sagada version, she is depicted very similarly as a poor, defenseless girl but very hard-working class. She is depicted also as innocent, obedient and respectful, pure and simple, and naïve and inexperience. Fukhan to the Bontok version is portrayed as a flaccid character and secondary to Lumawig only with no major active roles in the actions of the story.

Happy ending will not be awarded to any girl in an oral narrative if without working tough to deserve it. Overall, Fukhan's personalities as described from the Bontoc version, she is a girl who has to experience something very badly to be rewarded. On her situation, she has to suffer as what her sister and her brother Khumanab did to her at home or outside the house. Furthermore, she has to be passive, avoid talking back and, and simply, she has to wait unresponsively for her hero who will certainly rescues and live happily ever after with her as common finale to all oral lore.

Women personalities in Lumawig's story variants were characterized as ever calm and kind young maidens, which are also other archetypal illustrations of the female stereotypical characteristics. They are compliant, well-behaved, and respectful, and are obliged to help others in the household chores, or other people.

As for the physical appearance of Bugan in Besao version, she is depicted as a very stunning and proud good-looking daughter of a rich man, especially in connection with her eyes compared to the moon, and her smile that is very enchanting. Attractiveness as feminine characteristics is the most significant quality that a woman can possess in every oral narrative which frequently displays future happiness on the part of every attractive female character.

\section{Inference of Gender}

In the indigenous oral tradition literature among the Igorots, sexual role has clear, distinct features that usually reflect the roles and outlooks of every culture. Resulting to these features, there are common differences and constant customary portrayals of individual character personalities and manners that appear throughout oral narratives that caused the rise of gender stereotypes, which in turn gives impact to gender roles given to immortal characters in the different literary variants.

Numerous archetypes of men are established in the traditional oral texts of the Bontoks and the Kankanaeys particularly in the Lumawig literary variants. From these character representations, anybody can classify such characters through their physical features, and expect future activities and happenings. In circumstances such as this, it is easier to assign titles based on the characters' 
behaviors, giving their names such as The Lover, the Avenger, the Tutor, the Traitor, and so on among the male characters as classified by van Sweringen (1915).

The character of Lumawig can be basically shortened with a main, corresponding stereotypical characteristic which is considered heroic impression that displays the masculine characteristics considered in all areas as physically, relationally, mentally, and emotionally common to all literary variants. In the story, Lumawig acts in a way commonly required of his gender that through physicality, he possesses enormous power. Through capability, he is skillful in every battle and able to defend his community and people. Relationally, he is a role model with an upright leadership and adopts a prevailing outlook. With mentality, he thinks such situations through and focuses more on reasoning and decisions than on perception. It is of the last characteristic that Lumawig stereotypically lean in the direction of the adverse extreme. On the odd occasion, Lumawig expresses any nature of emotional expression, for fear of being judged unmanly. In the world of Lumawig, as a hero, being vulnerable is a weakness which is intolerable. Nevertheless, the characters of Fukhan, Bugan and Bogan in the literary variants about Lumawig are infrequently apprehended to the criteria similarly; however that is not to say that their characters do not have their own stereotypes to live up to.

Throughout the literary variants, the characters of Fukhan and her unnamed sister from the story "The Adventures of Lumawig" depict many of the characteristics commonly associated with the category of being a Virtuous Woman and the Sensuous Woman. In the case of these two gender stereotypes, Wolff (1972) as cited from Gailley (2017) mentioned that:

[There is] a peculiarity that can exist between good women—for whom [the male character] feels fondness and respect; and bad women who arouse [the male character] sexually; in psychological terms, the virtuous woman "reflects [the male character's] inbibitory tendencies-'super-ego" "while of the sensuous woman "reflects [the male character's] libidinal or "id' tendencies".

Fukhan, being a virtuous woman in the story, she is on the balance side of Lumawig who primarily acts as a collaborator and a motivating force for the Lumawig's honorable and decent benchmark and consistent reasoning power. In the other Lumawig's literary variants, though, both women (Fukhan and Bugan) seems on the Sensuous Woman as an alternative, they are motivating and encouraging Lumawig to act more following his primitive predispositions and characters, with a smaller amount of belief headed for intention or significance. But, majority of female characters in the Lumawig's literary variants can exemplify one overall stereotype of which to become a woman, "womanly" character personae should be retained.

Lumawig and Fukhan are depicted as respectable and noble persons and there must be the contradictory of Lumawig's compassionate, concerned, and benevolent features and Fukhan's innocent and hard-working characteristics, which represents Fukhan's unnamed sister and Khumanab, Lumawig's brother-in-law.

The sister and brother-in-law depiction is more or less the same, as they were described as jealous and insecure except of their physical appearance. The other versions (Sagada, Besao, and Sadanga) either do not concern their appearance at all not to the Bontoc version that Khumanab is described literally as the jealous one sanctioned to anger Lumawig all the time.

There is a striking difference evident in Khumanab's (Lumawig's brother-in-law) characteristics and demeanor as well which his appearance is the only discrepancy to Lumawig. While Lumawig is characterized as the good one, his brother-in-law embodies the opposite as the wicked and malevolent one.

In line with Khumanab's antagonistic characteristic, Fukhan's sister (who is unnamed in the story) is described as a lazy person without any concern on her sister that she always goes bathing in the river leaving Fukhan behind to do the picking of falatong (black beans). She is not interested in others' feelings. She left her sister in the fields and ran fast to tell their parents about the appearance of a certain man in the person of Lumawig. Similarly, Sadanga's version "Gomanab" is bitterly jealous of Lumawig's supernatural powers. 


\section{Gender Biases Portrayal}

The biased portrayals of the mythical characters can be considered the most famous mythological personalities in Igorot's world of oral lore. As the stories had been handed down from generation to generation, it is expected that literary variants were fabricated; nevertheless, its heroic theme is almost the same.

Regarding typical portrayals of cultural heroes in Lumawig literary variations, examples of such biases portrayals are the following: Firstly, passive, obedient, and submissive poor girls will only be rewarded. Secondly, in-laws and sisters are always evil as it is evident in Bacwaden's (2008) study (How He Sent His Family to Tinglayan):

"While they were living in Lanao, Lumawig's brothers-in-law were filled with envy. So around the house where he had celebrated his chomno (marriage feast), two of his brothers-in-law bung hot pepper."

Thirdly, beauty is always the maximum importance for women in every narrative, and lastly, substantial belongings are necessities in life. Concerning gender biases in the Lumawig variations proved that the roles the male characters portrayed are optimistic as active adventurers and leaders to the whole narrative whereas the female characters represented a passive and inferior roles of confidantes and partners or none and only a small part of female characters are described as courageous and independent or rather physically fit for a man's role.

It appears that Lumawig's stereotypical character is depicted as an immortal hero and the son of the great god Kafonyan who takes a journey and overthrows and overcomes all difficult hindrances before him. He plays a noteworthy character and role throughout the whole stories. It is obviously described from the tales that the only possible salvation of the Igorots particularly the Bontoks and the Kankanaeys is Lumawig himself, the only hero who can provide the people with happiness and welfare. The most interesting portion in connection with gender biases is the emphasis on the hero's "macho" image as even little girls in the contemporary eras are already guided to find an image similar to Lumawig's physical description that will render them the essential well-being that resolves protection of their gratification and serenity.

However, Lumawig is not depicted only as an immortal one; he is also depicted as a very handsome, spirited and enthusiastic, tough and sturdy, respectable and decent, strong leader, magnificent and splendid, enigmatic and shadowy, and wealthy and prosperous mortal in the Bontok version. Lumawig's immortal and omniscient abilities involved him to the Bontok's and Kankanaey's society and passionately attached him to the "natives". His inability to connect with the affairs of the Bontoks and Kankanaeys were depicted after he set sail his wife Fukhan and children to Tinglayan alone by themselves; allowed her to marry another man from another tribe; punishing the people of Can-eo, terminates all the associations he tries to uphold and sustain during his existence are considered to be his human-like capacities.

Lumawig's binary characteristics as mortal and immortal one reveal that his curved observation of reality demonstrates to be the contradictory factor of favorable, creating his skills poor and lowly through a deconstructive lens. As an immortal one, he has the essential gift foreseeing the future and experiences it, yet he wasn't able to stop the barbaric death of his sons in the hands of the people of Can-eo (a small village in Bontoc), he did not maintain his emotional relationships to Fukhan.

\section{Biases in Lumawig mythical variants}

Bias refers to the tendency to show prejudice against one group and favoritism towards another, or for one to be influenced so much by something that he or she does not judge things fairly. Biases spring up from the practice of stereotyping. Most people readily acknowledge the existence of stereotypes of race, ethnicity, age, social class, nationality, sexual orientation, region of the country, religion, and gender. Stereotypes are manifested in many ways: advertising, television, movies, music, and literature. Stereotypes abound in children's books, where women are mommies, children live at home with two parents, people are white, and where boys are active, have adventures, and solve problems while girls are passive, dependent, and fearful (Alsemi and Law, 1998). The book compiled by Henry Beard and Christopher Cerf enumerates so many biases but the researcher only focused on biases committed in the versions of the Lumawig myths. These are sexism, heightism, speciecism, socioeconomism, and lookism. 


\section{Sexism}

Sexism as Beard and Cerf point out is the stereotyping of males and females on the basis of their gender. It is considered to be the repression and domination of women by society in the belief that genders is a suggestion of ability (1992). The first manifestation of sexism in the stories is the implication that female is the weaker sex needing protection and special favors than male.

In Bontoc's version, it is analyzed that the role of Fukhan feels that her being a simple girl from a certain Bontoc village is equated to being frail and helpless and could not do anything but to wait for her savior in the person of an immortal god. Lumawig did not actually perform any spectacular feat, nor has he fought to win the maiden. The only thing that exists between Lumawig and Fukhan is mutual physical and behavioral understanding. It is precarious to use the word "love" because it is quite unrealistic for two people to love each other immediately at first encounter. In the Sagada and Sadanga version, Madadne, (Sagada version) Fatanga (Sadanga version) uses their authority over their daughters for their own personal motives and even Lumawig himself uses his authority over his wife Fukhan for his personal motive. In the stories, antagonist characters are described and also sexism is committed. The story readily paints in the mind of readers that all sisters-in-law and brothers-in-law are cruel and inconsiderate.

\section{Lookism}

The belief that appearance is an indicator of a person's value is considered to be a bias. It is the creation of the ordinary and typical description for beauty and appeal and the domination through stereotypes and simplifications of both those who do not fit the standard and those who do. In almost all folktales involving love affair between a man and woman, the woman has to be exceptionally beautiful for the prince to love her. In the Bontok's version, Lumawig knows the lovely maiden through the test he did, and he immediately asked her to marry him:

"Summoned Mr. Sun to sheen as scorching as it could, he sat viewing the two sisters at labor from dawn till the cool of daylight. He witnessed that one of the sisters was more hard-working and diligent than the other..." (Bontok version)

It is not only Lumawig who commits the bias of lookism here. In fact, Fukhan commits a bigger mistake in immediately thinking that she could trust the stranger when it was just their first meeting. To make matters worse, it is the first time for Fukhan to see an extraordinary person of the opposite sex, and it is surprising how she could readily agree to marry him. There could only be one reason for this: Fukhan finds the extraordinary physical appearance of Lumawig to be appealing to her.

Another scenario of lookism in the Bontok version seems to be that Lumawig and Fukhan who are pleasant to look at is kind-hearted while Khumanab and Fukhan's sister who are "ugly" are of disgraceful attitudes. The lookism in this scenario appears to be an indicator of a person's value is very much evident in the characters of Lumawig and Fukhan even in other variations: fields...

As he was relaxing on a platean overlooking the small village of Bontoc he saw two sisters working in the

Seeing Lumawig enter the house, Fatanga said, 'This is the man who should marry my danghter'. This bias is very much evident in other scenarios in the Bontok version.

He saw the young people of Balangao and said to bimself, "I will look for someone to court here." But when he looked again very carefully at them he noticed that they are having skin disease, and they were constantly scratching their heads and the lice were falling into their food.

Then Lumawig approached to examine the maidens of Talubin and was still at a far distance when he heard them talking and was confused to hear how they talk... seems like they are birds... "T won't marry here," be uttered.

\section{Heightism}

This is the discrimination committed especially against short people. It is quite difficult to ascertain the average or standard height for a person, though there are people who are exceptionally short for their age. In Lumawig's Bontoc version, one scenario that Lumawig did not stay in Sabangan to look 
for a wife is because the girls there aside are short people with short hair that he cannot distinguish them from the men of Sabangan. Readers could notice here the emphasis to the girl's size teaching them to regard anyone who is little and short to be funny:

When he was looking down at the river, he saw the village of Sabangan...

When he looked down at the young girls, he noticed that they are short with short hair. He couldn't distinguish which were women, and which were men.

\section{Speciecism}

When nonhuman animals and plants are oppressed by the prevailing species in the belief that the prevailing way of doing things is the superior way, the bias of speciecism is committed. The oppression could be in the form of slaughtering, eating, and hurting nonhuman animals (Beard and Cerf, 1992). It could also include treating them as pets or slaves, and another way of oppressing them is in questioning their nature as living things. To emphasize this point, this kind of bias is clear on the following scenario in the Bontok version.

"After the pursuit, the (laman) native pigs were slaughtered for the cañao (wedding feast). Lumawig ordered the chiefs of the barrio to share the meat equally, giving apiece to everyone present during the feast. The left over pig meat was placed in the fire cauldrons to cook it. He also ordered the individuals to fetch pine trees with which to support the cauldrons. However, the trees fetched were found to be very insignificant."

\section{Socioeconomism}

This is the oppression of the economically exploited or economically marginalized people. They are the victims of oppression, and they should not be blamed for their economic status. This kind of bias is seen in the Bontoc version to the people of Can-eo, part of Bontoc:

The people of Can-eo saw that the children of Lumawig had come back. for life after they chopped their bodies into pieces, they pursued once again by cutting their bodies up but scattered along the grounds.

Lumawig descended and said, "Since you persisted in murdering my sons, you shall never grow. And because you killed them while they were young, you shall never live long lives because you will also die."

There are at least five types of biases that are present in the oral text about "Lumawig" mostly in the Bontok version, considering that the story of Lumawig originally started in the village of Bontoc, Mountain Province.

\section{Linguistic sexism of Lumawig mythical variants}

\section{Analysis at the word level}

This portion of analysis focuses with the enquiry of gender bias at the level of the examination of individual words. The model centers on the more common and academic characteristics of sexism and provides an interpretation of generic procedure. Additionally, the researcher scrutinizes through the actions of the model specific types of sexist language-use. This proposal by Mills is concerned with the way that feminist critics have distributed with sexism in language, and the possessions which they claim this type of language-usage has on readers, predominantly the females (Mills, 1995). By exploratory on the Lumawig mythical variants, instances of usage such as the sex-specific pronoun usage, the misappropriation of generics, address languages and the negative portrayals of females and males in a variety of texts are non-existent.

\section{Analysis at the phrase/sentence level}

Analysis at the Level of Phrase/Sentence is focused with the way one can analyze language-use beyond the level of the word. In other words, it is much concerned with how the phrases and sentences were constructed in relation to their co-text, their context, the historical convention and also the contextual compulsory information. It was argued that how the semantic significance took place often comprises the development of meaning-production. In feminist analysis of sentences, some archaeological work is necessary to unearth the places where conceptual knowledge enlightens meaning (Mills, 1995). The subsequent exploration deals with the points that go beyond the wordlevel, i.e. phrase/ sentence levels: 


\section{Inferences}

Inferences are pieces of information that lead the reader to make expectations and draw conclusion or decision. In this respect, Boutonnet as cited from Darweesh and Gayadh (2016) describes inference as, "the key to uncovering the 'true' meaning" (Boutonnet, 2006). To demonstrate: Version)

She [Fukhan] then was a female who caused tempest because she did not follow Lumawig's advice. (Bontok

What is indirect and inferred in this sentence is that females are blamed of violating the rules of what Lumawig imposed after placing the big flat stone he carried from Lanao River to Chao-ey and named it "Khallat". It recommends that their demeanor is dishonest and debauched, and they do not exert to rule or stand by the law.

"In the Bontoc version tale, Lumanig constructed a container out of large pine log where he laid his wife and child. Then he sailed it to flow down along the rafting waters of the Chico River bound to Tinglayan, is an enemy territory."

\section{Metaphor}

In a certain culture, the most essential and important value will be comprehensible with the figurative organization of the most fundamental concepts in the culture. As Lakoff and Johnson (2003) describes metaphor as:

... [the] essence of appreciative and feeling one kind of thing regarding another. That is, it is associated with a particular rule of transference called metaphoric rule that indicates that the figurative meaning is derived from the literal meaning...

The following scenario from the Lumawig myths illustrates this:

When he was looking down at the river, he saw the village of Sabangan. He said, "I will search for someone to court here because wow, the people are fair in complexion with shiny bodies and when you look at them they are like pitch-pine wood". (Lumawig Myth).

So, it is said, she went quietly and peeped at him. He was using his whole body [to plow]. Even his ears were like two persons, while his hairs were like numerous workers plowing the field. (How Lumawig Left)

\section{Analysis at the discourse level}

Mills opined that analysis at the discourse level is an investigation of how the word and the phrase link with a larger view and concept of ideology through word-based patterns and structures. In other words, it connects framework of the effects of words across sentences or conversational turns with the contexts of larger social patterns (1995). Thus, such analysis is carried out above the sentence level. This section highlights the following areas:

\section{Characters}

According to Mills, the descriptions of clothes and facial characteristics are used to 'point to' the type of overall assessment that the reader is expected to make of the character (1995). The following sentences from Lomawig's mythical variants clarify the world of sexism in which the characters live:

\section{By Appearance}

Mills (1995) argues that female characters tend to be described concerning their appearance while men are often described by their personality. The following are female descriptions taken from the Lumawig mythical variants.

\section{Gender portrayal of female characters}

The main female characters are depicted very similarly in all versions except in Sagada version which are typical examples of the stereotypes. They are represented as poor, defenseless girls but very hardworking classes. They are depicted as innocent, obedient and respectful, pure and simple, and naïve and inexperience. 


\section{Bontok Version}

Fhukhan is portrayed as a flaccid character and secondary to Lumawig only with no major active roles in the actions of the story. Not only that she is passive and dutiful, she is also very virtuous and although her life is tough as she was introduced in the beginning of the story, she does not have the attitude to complain, instead, she insists herself in helping other people instead. The only opportunity to flee from a biased life full of hopelessness in the hands of her family is Lumawig.

It seems that Fukhan cannot be awarded a happy ending without being an industrious one that she has to merit it. In the whole narrative, Fhukan's description, as a girl experiencing something very badly having to suffer and be treated as a slave as what her sister and her father Khumanab did to her, she has to be rewarded in the end. Furthermore, she has to be passive, avoid talking back and, at the same time, she simply has to wait patiently for her man who will certainly come and live "happily ever after" with her.

Fhukan is also portrayed as a servant staying inside the house doing such Herculean household chores while Lumawig is away. This is associated to a mother's role, women's primary role who in their lives are to be mothers, staying at home and keeping the household in order to satisfy their husband's needs, which is one of the most prevalent preconceptions or biases against women. It recommends and submits that the only goal a girl should be interested in is to be the right mother, preferably attractive, and always stays at home.

Fhukan's sister's depiction is more or less the same, as she was described as jealous and insecure except of her physical appearance. The other versions (Sagada, Besao, and Sadanga) either do not concern their appearance. The sister is also very jealous of Fukhan as to why she was chosen by Lumawig, and yet she is the older one. However, even though there is no convincing and influential motivation clarified for that so much this can be understood and deduced that women are interested in handsome men especially if they are well-built.

It is understandably interpreted that Fukhan's sister serve as her foil, serving as a contrast and a complete reverse to her personality as a main female character. As Neikirk (2014) mentions, there is a noticeable connection between the positive traits and between the negative characteristics, which can be understood that "ugly women are source of suspicion". If a woman is ugly she is automatically considered evil or, at least, peculiar, and she must be jealous and insecure of more attractive women.

\section{By Behavior}

Male characters on the other hand are described by their character or behavior. Here are some transcripts from the stories:

\section{Lumawig Myth}

That night surprisingly his brother-in-law Khumanab showed his malice by sticking chili peppers into cracks at the door and at the side of the house. It is essential to discuss dealing with the Khumanab's punishment in the narrative since the Bontok version stresses that the brother-in-law has to be punished of the evil acts he bestowed upon Lumawig. Regarding the moral lesson, it implies that the good ways always prevails over the evil ways; however, regarding gender biases, this indicates that good characteristics always defeat the bad characteristics. The good characteristics stress the importance of Lumawig's appearance and his dutiful role in the Bontok society while Khumanab's evil behaviors stress the bad characteristics.

The appearance of Khumanab is the only disparity to Lumawig's role, there is outstanding different evidence in the brother-in-law's characteristics and behavior as well. While Lumawig represents the good in general, his brother-in-law embodies the evil.

\section{Fragmentation}

As mentioned by Mills (1995), fragmentation is the method where characters are described regarding their body-parts instead of as people to refer to starkly juxtaposed bits and pieces in the narratives, to demonstrate: 
The youngest child was divided in two. But Kafonyan provided the missing parts of the balved bodies creating two babies named Bangan and Lomauig. Bogan had Bangan and Kafonyan had Lomanig whom he took with him to beaven. (The Birth of Lumawig)

So, it is said, she went quietly and peeped at him. He was using his whole body [to plow]. Even his ears were like two people, while his hairs were like numerous workers plowing the field. Then she went back and coughed but Lumawig knew what she had done. And, it is said, when she reached the field, Lumawig was whole again. (How Lumawig Left)

\section{Conclusion}

In the case of the Lumawig mythical variants studied, there is no occurrence of language sexism in the word-level. However, there are occurrences of language sexism particularly in the way males and females are described in the sentence and discourse level. The trend in the descriptions is physical appearance for females and behavior for men.

For the gender biases that are based from the handbook of Henry Beard and Christopher Cerf, there are five of them that include: (a.) Sexism where a woman is always expected to be caring and nurturing what was shown in the different versions of the story; (b) Speciecism where animals and plants were slaughtered, destroyed and abused; (c) Socioeconomism where discrimination against the economically marginalized was shown in the Bontoc's version; (d) Lookism where other girls from different places mentioned in the story became the subject of discrimination due to their appearances; (e) Fukhan and Lumawig, the main characters have to be of higher physical stature than the ordinary; and (f) Heightism girls in Sabangan (a place near Bontoc) became the object of discrimination just because they are short.

\section{References}

Alsemi, D., and Law, A. (1998). Questions of gender: perspectives and paradoxes. USA: McGraw -Hill.

Animasahun, O. (2015). Sexist language in Nigerian newspapers: a case study of the Punch and the Guardian newsapers. Journal of Humanities and Social Sciences, 20(1), 65-75. doi:10.9790/0837-20126575.

Bacwaden, J. O. (2008). The Lumawig Bontoc Myths. Philippine Studies, 45(3), 329-352.

Beard, H., and Cerf, C. (1995). The official politically correct dictionary and handbook. New York: Villard Books.

Bokhari, M., and Masood, S. (2018). Study of mythology: In the context of structuralists theoretical framework. International Journal of Applied Research and Studies, 4(2), 91-94.

Botengan, C. (1976). Bontoc life-ways: a study in education and culture. Manila: Capitol Publishing House, Inc.

Campbell, J. (2008). The hero with a thousand faces. Novato, CA: New World Library.

Çer, E. (2016). The significance of the literary works based on the principle of the accordance with the child in Turkish education. Primary School Online, 15(4), 1399-1410.

Chakas, R. and Mi-ing, J. G. (2017). "Stone Wars": The Fagfagto's Impact on Socialization. A paper presented during the $2^{\text {nd }}$ International Conference on Cordillera Studies. Baguio City, Philippines.

Chakas, R. and Mi-ing, J.G. (2017). The Bontoc Ato System: Understanding men's Traditional Upbringing. A paper presented during the $2^{\text {nd }}$ International Conference on Cordillera Studies. Baguio City, Philippines.

Corpuz, S. (2000). Critical Analysis of Selected Tales from James Finn's Garner Politically Correct Bedtime Stories. (Unpublished Master's Thesis). Baguio Colleges Foundation.

Cranny-Francis, A., Waring, W., Stavropoulos, P., and Kirkby, J. (2003). Gender Studies: Terms and Debates. New York: Palgrave Macmillan.

Darweesh, D., and Ghayadh, H. (2016). Investigating Feminist Tendency In Margaret Atwood's "The Handmaid's Tale” In Terms Of Sara Mills' Model. A Feminist Stylistic Study. British Journal of English Linguistics, 4(3), 21-34.

Dixon, E. (2017). Folklore and Mythology in Neil Gaiman's American Gods. (Unpublished Master's Thesis). University of Oregon.

Dovidio, J. F., Evans, N., and Tyler, R. B. (1986). Racial stereotypes: the contents of their cognitive representation. Journal of Experimental Social Psychology, 22, 22-37.

Fagsao, D. (2015). Kankanaey and Bontok Popular Contemporary Songs: Reflections of Igorot Social Conditions and Values. (Unpublished Master's Thesis). MPSPC

Fetalvero, C. (2016). Linguistic Sexism: A Study of sexist language in selected Tinguian Literature. A Paper presented during the HARDECC regional research conference, La Trinidad, Benguet Province.

Fraenkel, G. (1967). Language in culture. Massachusetts: Ginn and Company.

Green, A. (1997). An encyclopedia of beliefs, customs, tales, music, and art. ABC-CLIO, Inc. Santa Barbara, California, 93116-1911.

Heilman, M. E. (2001). Description and prescription: How gender stereotypes prevent women's ascent up the organizational ladder. Journal of Social Issues, 57, 657-674.

Lakoff, G. and Mark, J. (2003). Metaphors we live by. London: The university of Chicago press. 
Manochon, M. (2009). Interpreting Selected Myths as Expression of Bontoc Worldview. (Unpublished Master's Thesis). Univ. of the Philippines, Baguio City.

Mastud, S. (2017). Reinterpretation of Myth and History to Reconstruct the Past Reality : Shashi Tharoor's The Great Indian Novel. The Criterion: An International Journal in English, 8(3).

Mayen, R. C., and Burges, B. M. (2014). Analysis of current gender stereotypes. Annals of Psychology, 30(3), 1044-1060.

Mills, S. (1995). Feminist stylistics. London \& New York: Routledge

Mills, S. (2008). Language and sexism. Cambridge: Cambridge University Press.

Moore, T. (2014). Sex roles. The Gale Encyclopedia of Psychology. Bonnie. Strickland (ed). Detroit: Gale, 2001. 578-581. Gale Virtual Reference Library. Web.

Moya, M. (2003). El análisis psicosocial del género. In J. F. Morales \& C. Huici (Eds.), Estudios de Psicología Social (pp. 175-221). Madrid: UNED.

Moya, M., \& Puertas, S. (2003). Definición de sexismo y conceptos relacionados. In D. Páez, I. Fernández, S. Ubillos, \& E. Zubieta (Coords.), Psicología Social, Cultura y Educación (pp. 208-223). Madrid: Prentice Hall.

Al-Nakeeb, O. (2018) Fragmentation of the Female Characters in Final Flight from Sanaa: A Corpus-based Feminist Stylistic Analysis. International Journal of Applied Linguistics and English Literature, 7(3), 221-230.

Puma-at, K. (2015). Literary Text V ariants in the Lumawig Mythology. (Unpublished Master's Thesis). MPSPC.

Neikirk, A. (2014)... "Happily Ever After" (or What Fairytales Teach Girls About Being Women). Anthropology $324 \quad$ Essay, 38-42. Retrieved from https://hilo.hawaii.edu/campuscenter/hohonu/volumes/documents/Vol07x07HappilyEverAfter.p df.

Sabater, C. (2015). Research on sexist language in EFL literature: towards a non-sexist approach. Porta linguarum, 187-203.

Safaa, M. A. (2015). Children literature based program for developing EFL primary pupils' life skills and language learning strategies. English Language Teaching, 8(2).

Sanauddin, N. (2015). Proverbs and Patriarchy: Analysis of linguistic sexism and gender relations among Pashtuns of Pakistan. (Unpublished Doctoral Thesis). University of Glasgow, Scotland. Retrieved from http://theses.gla.ac.uk/6243/.

Shi, W., and Zhang, H. (2017) A Sociolinguistic Study of Linguistic Sexism in English Proverbs. Saudi Journal of Humanities and Social Sciences, 2(6), 459-461.

Short, M., and Semino, E. (2008). Evaluation and stylistic analysis. In Willie Van Peer(ed.), The Quality of Literature Linguistic studies in literary evaluation. Amsterdam: John Benjamins Publishing Company.

Sinan, A. et al. (2017). Teacher's Views Regarding the Place of Children's Literature in First Language Education. Journal of Education and Training Studies, 5(12).

Steele, C. M. (1997). A threat in the air: How stereotypes shape intellectual identity and performance. American Psychologist, 52(6), 613-629.

Veselá, A. (2014). Gender Stereotypes in Fairy Tales. (Diploma thesis), Masaryk University.

Wolff, G. (1972). A Mirror for Men: Stereotypes of Women in Literature. The Massachusetts Review, 13(1), 205218.

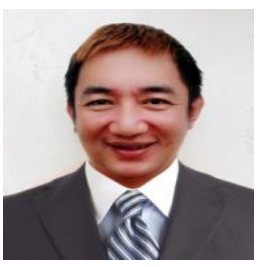

DR. JONNELLE DESIERTO FAGSAO is presently an assistant professor, choral director, and adviser of the singing ambassadors of MPSPC (Mt. Prov. State Polytechnic College), the MPSPC MINSTRELS. Dr. Fagsao holds a Master's Degree in Teaching English and Doctoral Degree in Educational Management. He wrote, presented, and published researches internationally related to his field of expertise - language, literature, and indigenous music of the Bontoks and Kankanaeys in the Philippines. 